\title{
Does Resection of Heterotopic Ossification of the Elbow Result in Satisfactory Functional Outcomes?
}

(i) Mehmet KAPICIOĞLU1, id Yavuz SAĞLAM², id Ali ERŞEN³, id Ata Can ATALAR33, id Mehmet DEMIRHAN4,

(iD Hayati DURMAZ3

${ }^{1}$ Bezmialem Vakıf University Faculty of Medicine, Department of Orthopedics and Traumatology, İstanbul, Turkey

${ }^{2}$ Biruni University Faculty of Medicine, Department of Orthopedics and Traumatology, İstanbul, Turkey

3̇istanbul University İstanbul Faculty of Medicine, Department of Orthopedics and Traumatology, İstanbul, Turkey

${ }_{4}^{4}$ Koç University Faculty of Medicine, Department of Orthopedics and Traumatology, İstanbul, Turkey

\section{ABSTRACT}

Objective: Heterotopic ossification (HO) is a common cause of elbow stiffness following surgical treatment of elbow trauma. In this study, our aim was to evaluate the mid-term functional outcomes of open surgical procedures for $\mathrm{HO}$.

Methods: In this retrospective study approved by the institutional review board (IRB), all patients who were diagnosed as having stiff elbow due to $\mathrm{HO}$ and underwent surgical resection at a single institution from 2006 to 2013 were included. Intrinsic (inside the joint) pathologies were excluded. Range of motion (ROM) in sagittal and coronal planes, complications, functional scores such as Quick Disabilities of the Arm, Shoulder and Hand Score (Q-DASH), and Mayo Elbow Performance Score (MEPS) were evaluated before and after surgery.

Results: There were 19 patients (16 males, 3 females) with a mean age of 38.6 (range 15-69) years. At an average follow-up of $36 \pm 8$ months, the mean flexion-extension arc was improved from $27.4^{\circ}$ to $99.2^{\circ}(\mathrm{p}<0.001)$ and mean supination-pronation arc was improved from $48.9^{\circ}$ to $102.3^{\circ}$ $(\mathrm{p}<0.001)$. The mean Q-DASH score was decreased from 68.2 to 17.1 ( $\mathrm{p}<0.001)$ and mean MEPS was improved from 37.5 to 85.6 ( $\mathrm{p}<0.001)$.

Conclusion: Excision of heterotopic bone and releasing contracted tissues around elbow can provide a substantial increase in range of motion and improvement in clinical scores.

Keywords: Heterotopic ossification, elbow stiffness, elbow trauma, open surgical release

\section{Introduction}

Heterotopic bone formation plays a major role in the extrinsic causes of stiff elbow and has been depicted to arise in several situations including traumatic (intra-articular or extra-articular fractures, dislocations, post-surgery), neurogenic (head or spinal trauma) and congenital (fibrodysplasia ossificans progressiva) conditions andsevere burns (1-5). The pathophysiology of heterotopic ossification $(\mathrm{HO})$ still remains unclear and the condition is likely to be multifactorial $(4,6,7)$. Histologically, $\mathrm{HO}$ is the formation of mature lamellar bone in extraosseous soft tissues (8). The energy of trauma seems to be the major determinant of $\mathrm{HO}$ formation. Low energy traumas like simple elbow dislocation cause $\mathrm{HO}$ formation in 3\% of cases and the prevelance increases up to $45 \%$ with high energy distal humerus fractures $(5,6,9)$.

HO prophylaxis is controversial and could only be effective by understanding patients' risk factors, utilizing less invasive surgical techniques and implementing perioperative non-steroidal antiinflammatory drugs (NSAIDs). Low dose irradiation can be preferred in selected cases $(6,7,10)$. Extensive $\mathrm{HO}$ can result in clinically significant contractures or complete ankylosis of the elbow (8). If elbow motion does not progress with non-operative

Address for Correspondence: Yavuz Sağlam, Biruni University Faculty of Medicine, Department of Orthopedics and Traumatology, İstanbul, Turkey

Phone: +90 5363205005 E-mail: yavuz_saglam@hotmail.com ORCID ID: orcid.org/0000-0003-4475-8211

Cite this article as: Kapıcıoğlu M, Sağlam Y, Erşen A, Atalar AC, Demirhan M, Durmaz H. Does Resection of Heterotopic Ossification of the Elbow Result in Satisfactory Functional Outcomes? Bezmialem Science 2019;7(2):124-31. 
treatment (physical therapy and splinting), removal of heterotopic ossifications should be taken into account at an appropriate time $(4,11)$. Although surgery is technically challenging, recent studies revealed significant improvements in range of motion after excision of the heterotopic bone with early assistive physical therapy and splinting (11-14).

We, therefore, aimed to evaluate the mid-term functional outcomes of open surgical procedures for $\mathrm{HO}$, regarding the resection of heterotopic bone formation and the release of contracted tissues around the elbow.

\section{Methods}

This is an institutional review board (IRB) approved retrospective study in which all patients who were diagnosed as having stiff elbow due to $\mathrm{HO}$ and underwent surgical resection at a single institution from 2006 to 2013 were included. Patients with the diagnoses of intrinsic type stiffness such as osteochondritis dissecans, osteoarthritis, inflammatory arthritis, intra-articular fractures, synovial chondromatosis were excluded. Patients with severe elbow instability or deformity, and with skeletal immaturity were also excluded.

Main indication for surgical excision was clinically symptomatic or disabling $\mathrm{HO}$ of the elbow. The patients' demographics, etiology of $\mathrm{HO}$, surgical approach and treatment modality, range of motion (ROM) in sagittal and coronal planes, type of splint used, complications, functional scores such as Quick Disabilities of the Arm, Shoulder and Hand Score (Q-DASH), and Mayo Elbow Performance Score (MEPS) were evaluated. All clinical and functional evaluations were done at two time points; before the operation and at the latest follow-up. All the joint motions were measured utilizing a goniometer. Heterotopic bone formation was classified by the Hastings and Graham classification preoperatively on X-rays (15) (Table 1). Three dimensional computerized tomography (CT) was obtained in selected patients.

\section{Surgical Procedure}

The preoperative evaluation of the initial pathology and the location of the $\mathrm{HO}$ were the major determinants of the preferred surgical approach (Figure 1). Each patient was placed in the supine position under general anesthesia. An inter-scalene

Table 1. The Hastings and Graham classification

\begin{tabular}{l|l}
\hline Radiographic and Anatomic Findings & Class \\
\hline $\begin{array}{l}\text { Heterotopic ossification without functional limitation } \\
\begin{array}{l}\text { Partial limitation of (flexion or extension) and/or } \\
\text { (pronation or supination) }\end{array}\end{array}$ & I II \\
$\begin{array}{l}\text { Ankylosis with total limitation of (flexion or extension) } \\
\text { and/or (pronation or supination) }\end{array}$ & III \\
$\begin{array}{l}\text { Sub-classification of Class II and Class III } \\
\text { Limitation in flexion/extension plane } \\
\text { Limitation in supination/pronation plane }\end{array}$ & Subclass \\
Limitation in both planes & A \\
\hline & B \\
\hline
\end{tabular}

catheter was placed for pain relief and immediate initiation of physical therapy postoperatively. A tourniquet was applied and the arm was draped free. Firstly, a lateral incision was performed and the lateral extensors (extansor carpi radialis longus and bracioradialis muscles) were first subperiosteally elevated, and the anterior capsule of the elbow joint was exposed (Figure 2 ). The capsule was then elevated from the lower end of the humerus, exposing the radiocapitellar joint. Debridement of the joint was performed in combination with anterior capsulectomy. If the radial head was hypertrophied or deformed, it was excised to improve the range of motion. A retractor was used during the entire procedure to protect the neurovascular bundle. A subperiosteal dissection provides the exposure of the posterior humerus and release of the capsular adhesions (Figure 3). By the removal of the fibrous tissues from the olecranon fossa, further extension of the elbow can be achieved. Sometimes the tip of the olecranon process was osteotomized and removed. Then,

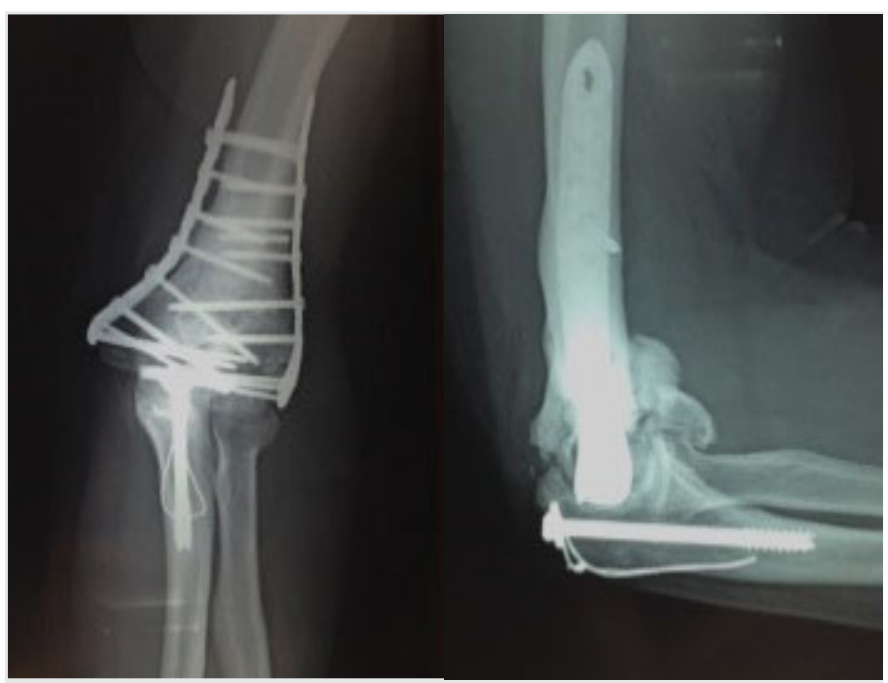

Figure 1. Previously operated distal humerus fracture with Hastings and Graham class 2A heterotopic ossification

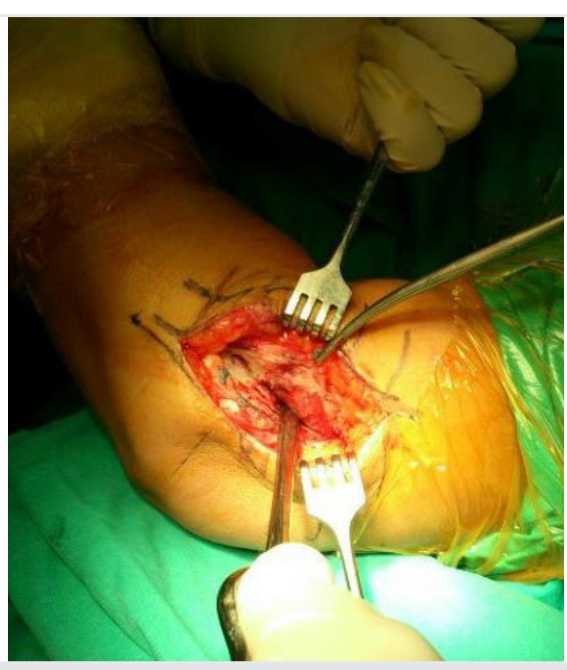

Figure 2. Lateral incision, subperiosteal elevation of lateral extensors (extansor carpi radialis longus and bracioradialis muscles) and dissection of the anterior capsule 
medial incision was performed and ulnar nerve was exposed and protected (Figure 4). Next, the flexor and pronator muscle origins were subperiosteally detached and the anterior capsule was stripped with the periosteum from the distal end of the humerus. Further inspection of the humero-ulnar joint was done to find any bony blocks. Any extra-articular ossified masses or osteophytes were excised. The collateral ligaments were released but preserved in selected cases. To avoid bony avulsion, release of the collateral ligament may be necessary. After the soft tissue was completely released, the remaining bony blocks were excised. A V-Y plasty of triceps can be helpful to gain more flexion if flexion more than $90^{\circ}$ is not possible due to tightness of the tendon out in this step. Finally, flexion and extension of the elbow were checked passively to evaluate the gain in movement (Figure 5). A meticulous bleeding control should be carried out

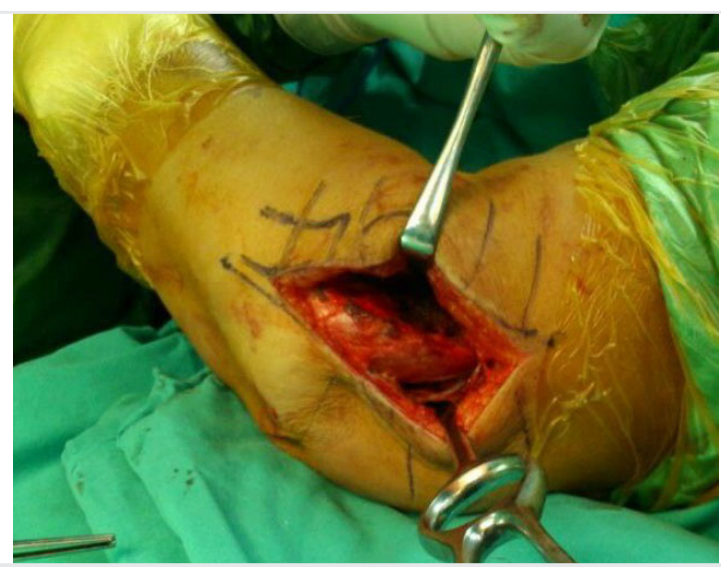

Figure 3. Elevation of the capsule from the lower end of humerus, radiocapitellar joint debridement in combination with anterior capsulectomy. Neurovascular bundle protection by a retractor. Dissection of the posterior aspect of the humerus to free the capsular attachment. Excision of fibrous tissues and loosing bodies from the olecranon fossa

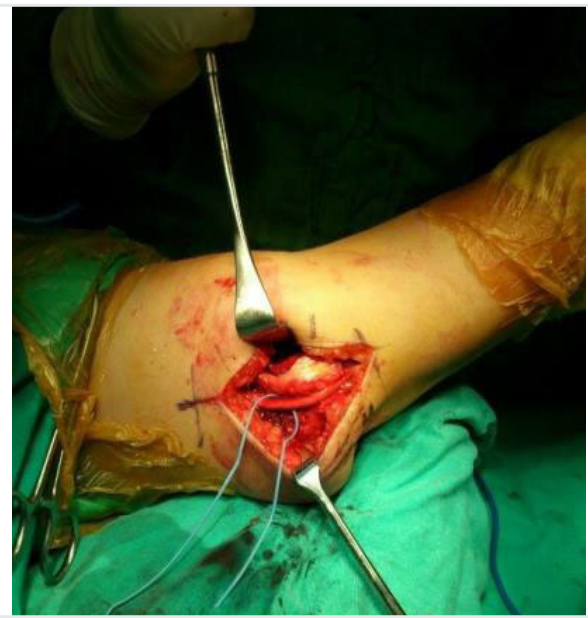

Figure 4. Medial incision, ulnar nerve dissection and protection. Subperiosteal elevation of the flexor and pronator muscle origins and anterior capsule. Further inspection of the humero-ulnar joint to find any bony block, loosing body or fibrous tissue after the pneumatic tourniquet is released. Subcutaneous ulnar nerve transposition was performed if necessary. After surgery, the wound was closed with suction drainage. The arm was placed in a long arm splint in full extension (Figure 6). A single posterior approach can also be used in particular patients, especially in the presence of a posterior bar between the olecranon and distal humerus. Another case, who underwent lateral and medial release with heterotopic ossification removal is illustrated in Figure 7.

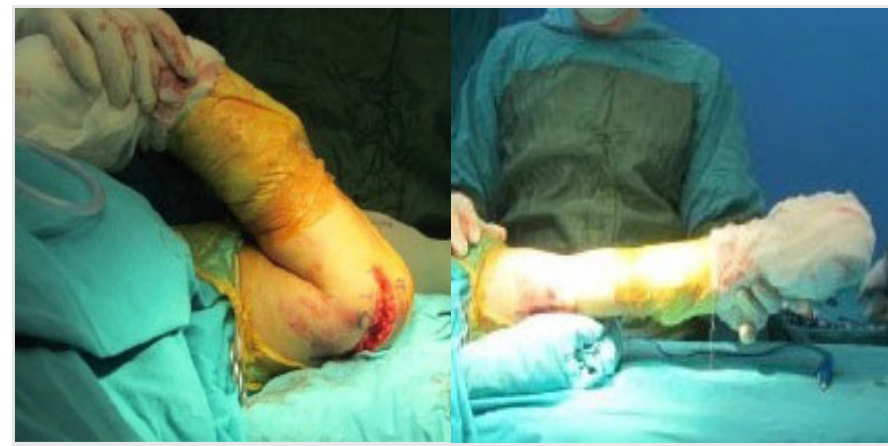

Figure 5. Final inspection of the flexion and extension of the elbow passively

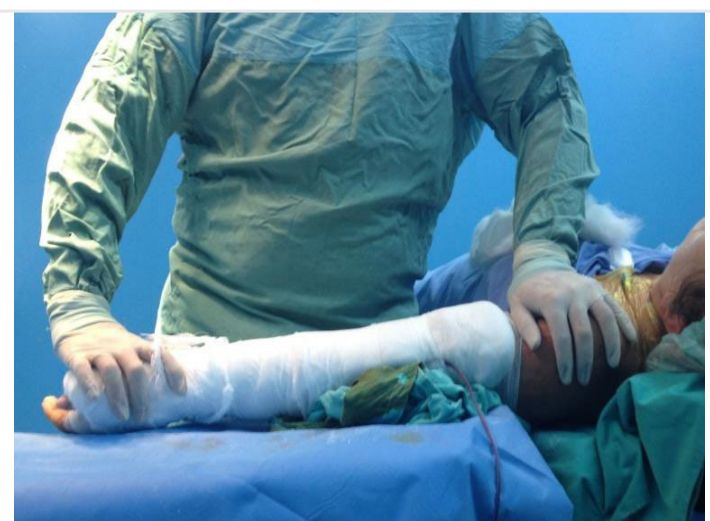

Figure 6. Placement of the arm in a long arm splint in full extension

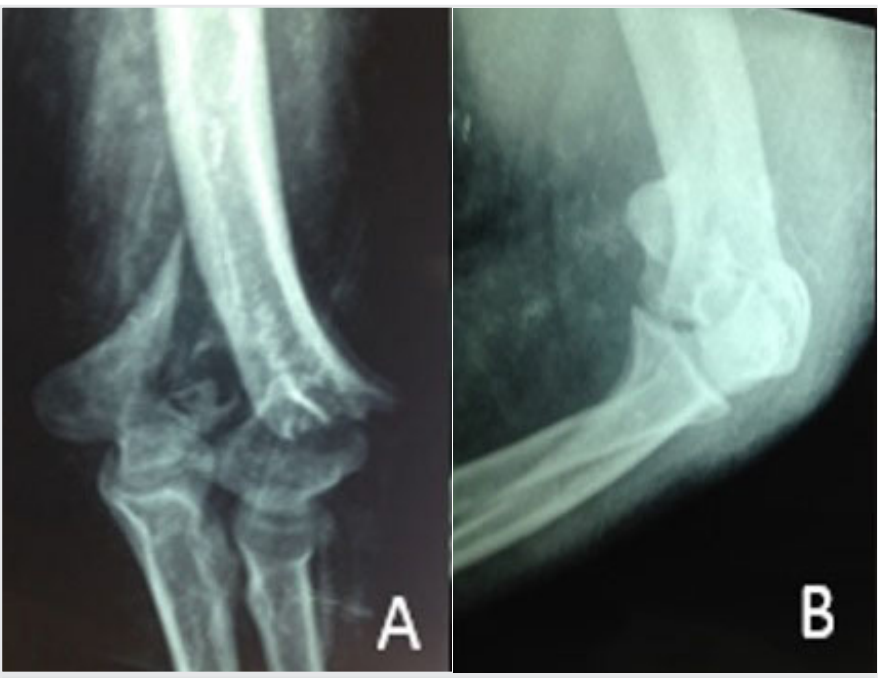

Figure 7 A-B. Initial distal humerus T type fracture 


\section{Post-operative Regimen}

Post-operative physiotherapy and medication were chosen for each case upon the pre-operative and peri-operative evaluation

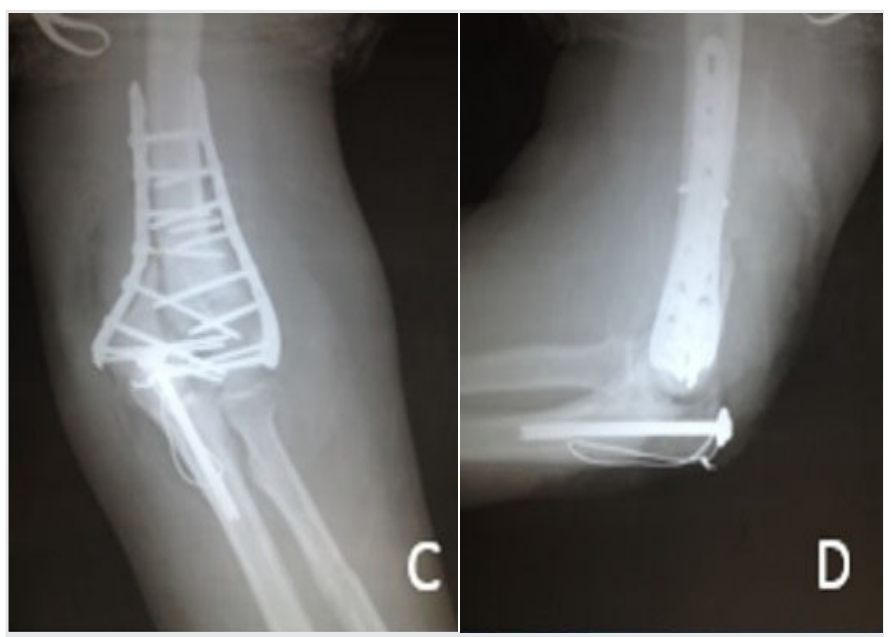

Figure 7 C-D. Intra-operative X-ray of distal humerus internal fixation as well as olecranon osteotomy

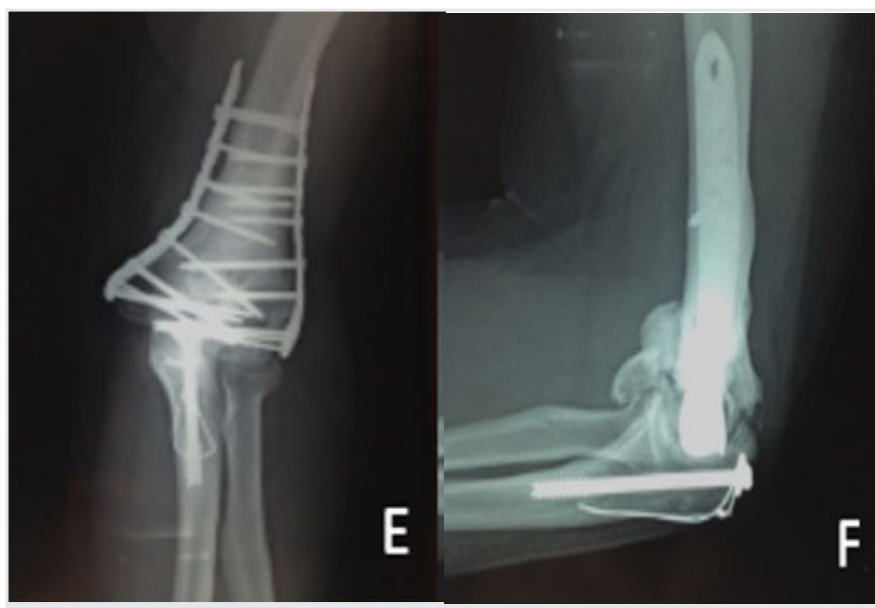

Figure $7 \mathrm{E}-\mathrm{F}$. Two year post-operative $\mathrm{x}$-rays showed severe heterotopic ossification formation especially around anterior elbow capsule

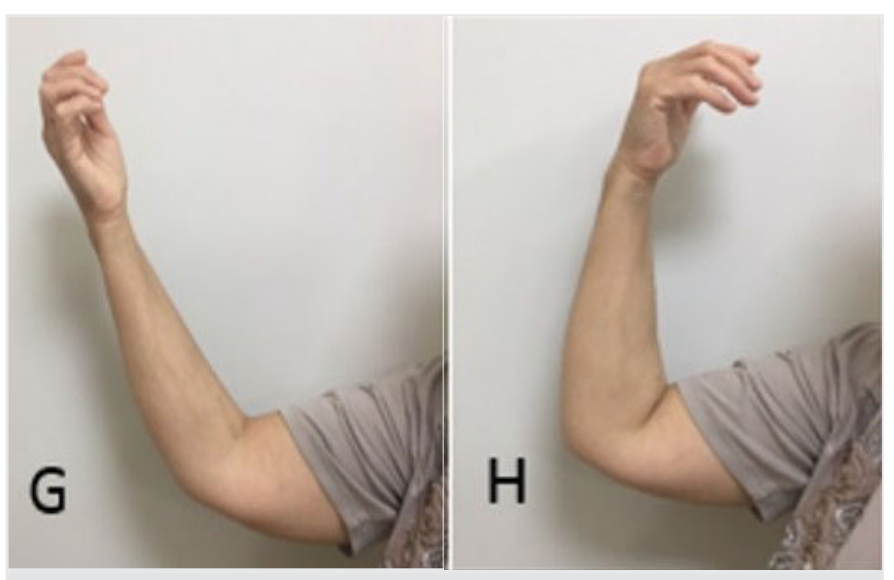

Figure $7 \mathrm{G}-\mathrm{H}$. Limited elbow range of motion due to heterotopic ossification and joint capsule contracture of the pathology. Pain relief was obtained by using inter-scalene catheter and intravenous ports. Drains were discontinued and early active assistive motion and continuous passive motion (CPM) exercises for flexion-extension and supination-pronation within tolerable limits of pain were initiated one day after surgery under the supervision of the physiotherapist. Nighttime splinting was continued for the deficient in motion for 3 weeks.

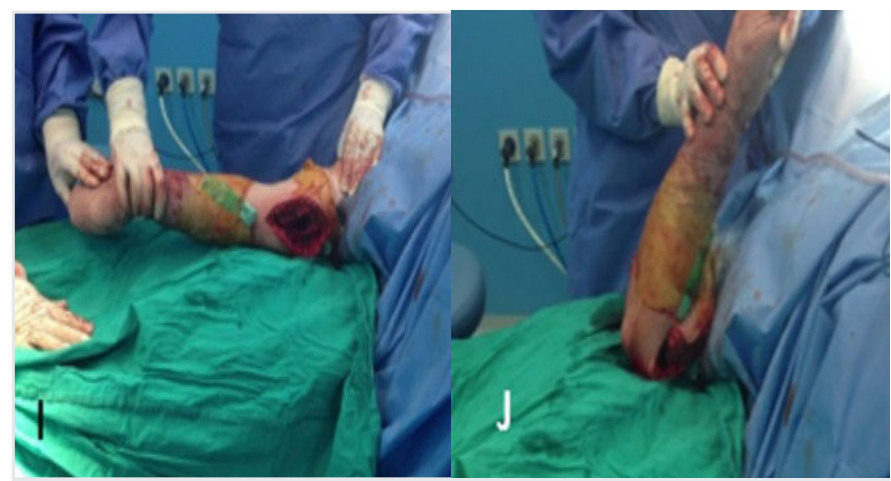

Figure $7 \mathrm{l}$-J. Increased elbow range of motion after medial and lateral release, and removal of heterotopic tissues

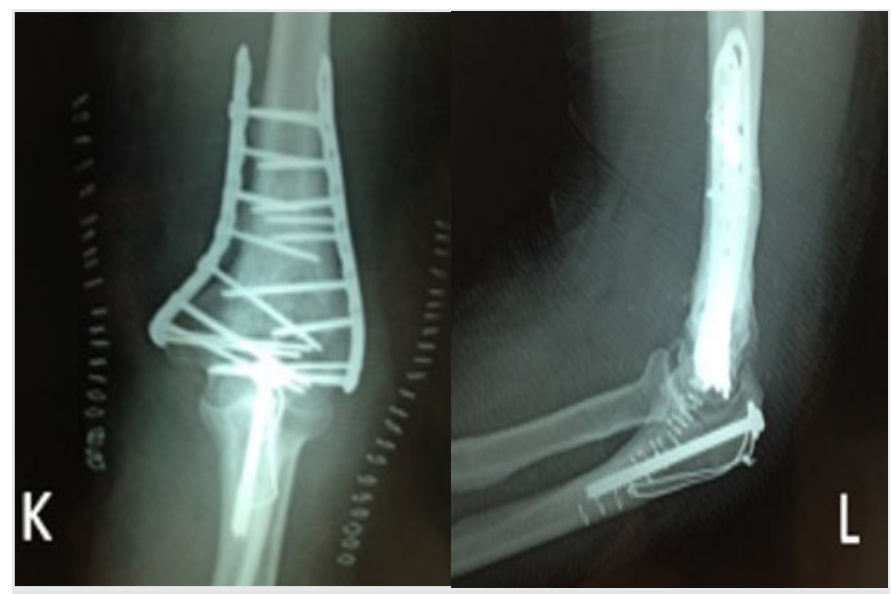

Figure 7 K-L. Early post-operative $x$-ray showed sufficient removal of heterotopic bones

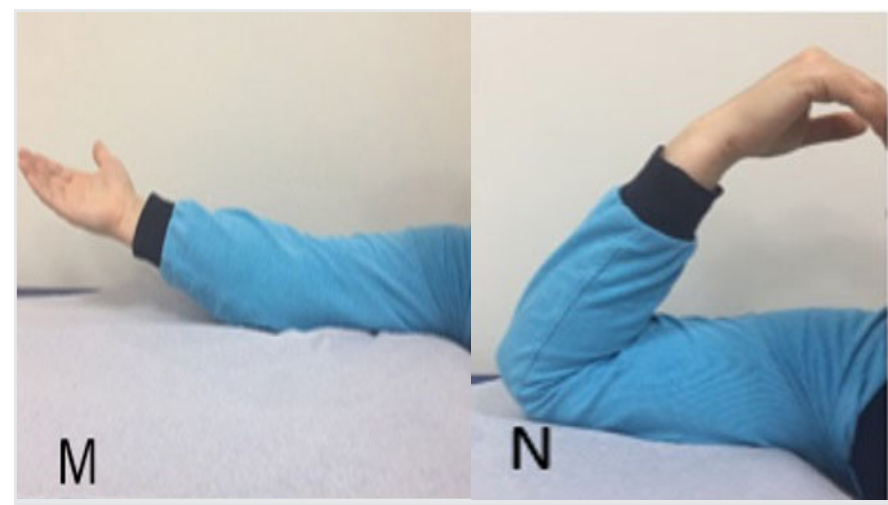

Figure $7 \mathrm{M}-\mathrm{N}$. Satisfactory elbow range of motion noticed one year after removal of heterotopic tissues and capsular release 
All the patients received oral NSAIDs (indomethacine $75 \mathrm{mg}$ per day) for postoperative pain relief and to prevent the recurrence of HO. The catheters were discontinued 12 hours before discharge. A single low dose (700 cGy) of radiation therapy (RT) was applied in selected cases on the day of surgery. The physical therapy and medication regimen were continued for at least 6 weeks postoperatively. Patients were followed closely for the recurrence of stiffness.

\section{Statistical Analyses}

Statistical analyses were performed using student t-test for parametric data, the Mann Whitney U (Wilcoxon rank test) and Kruskal Wallis test for non-parametric data as appropriate. SPSS Version 20.0 (SPSS Inc, Chicago, IL, USA) was used; a p value less than 0.05 was considered significant.

\section{Results}

There were 19 patients (16 males, 3 females) with a mean age of 38.6 (range 15-69) years at the time of surgery. The etiology of the $\mathrm{HO}$ formation was operated extra-articular distal humerus fracture in 8 patients, complex elbow dislocation in 4 patients, isolated head trauma and long term intensive care administration in 4 patients, repetitive low energy trauma in 3 patients. The preoperative mean flexion-extension arc was $27.4^{\circ}$ and supinationpronation arc was $48.9^{\circ}$. According to the Hastings and Graham classification; heterotopic bone formation was $2 \mathrm{~A}$ in 5 patients, $2 \mathrm{C}$ in 6 patients and 3C in 8 patients. Pre-operative mean Q-DASH score was 68.2 and MEPS was 37.5. Radial head resection was performed in 13 patients. Patient demographics and surgical details can be seen in Table 2 .

Table 2. Demographic and surgical details of the patients

\begin{tabular}{|c|c|c|c|c|c|c|c|c|}
\hline & Initials & Sex & Age & Etiology & $\begin{array}{l}\text { Surgical } \\
\text { approach }\end{array}$ & $\begin{array}{l}\text { The hastings and } \\
\text { graham } \\
\text { classification }\end{array}$ & $\begin{array}{l}\text { Ulnar } \\
\text { nerve } \\
\text { transposition }\end{array}$ & $\begin{array}{l}\text { Radial head } \\
\text { resection }\end{array}$ \\
\hline 1 & UK & M & 16 & Simple elbow dislocation & Combined** & Class IIA & - & - \\
\hline 2 & MO & M & 21 & Operated distal humerus fracture & Posterior & Class IIC & + & + \\
\hline 3 & OS & M & 23 & Head trauma and ICU* administration & Posterior & Class IIIC & + & + \\
\hline 4 & AK & M & 30 & Simple elbow dislocation & Lateral & Class IIC & - & + \\
\hline 5 & MBM & M & 32 & Head trauma and ICU* administration & Posterior & Class IIC & + & + \\
\hline 6 & KS & M & 35 & Complex elbow fracturedislocation & Combined** & Class IIIC & - & + \\
\hline 7 & HM & M & 37 & Complex elbow fracturedislocation & Combined** & Class IIC & + & + \\
\hline 8 & NO & M & 37 & Head trauma and ICU* administration & Posterior & Class IIIC & + & + \\
\hline 9 & TD & M & 37 & Operated distal humerus fracture & Posterior & Class IIA & + & - \\
\hline 10 & $\mathrm{CY}$ & M & 41 & Operated distal humerus fracture & Posterior & Class IIA & - & - \\
\hline 11 & HY & $\mathrm{F}$ & 41 & Operated distal humerus fracture & Posterior & Class IIA & + & - \\
\hline 12 & HG & M & 43 & Operated distal humerus fracture & Posterior & Class IIIC & - & + \\
\hline 13 & DD & M & 43 & Complex elbow fracturedislocation & Combined** & Class IIC & + & + \\
\hline 14 & TT & M & 48 & Simple elbow dislocation & Combined** & Class IIC & - & + \\
\hline 15 & GM & $\mathrm{F}$ & 50 & Complex elbow fracturedislocation & Combined** & Class IIIC & + & + \\
\hline 16 & AK & M & 69 & Operated distal humerus fracture & Posterior & Class IIA & + & - \\
\hline 17 & TO & M & 42 & Head trauma and ICU* administration & Posterior & Class IIIC & + & + \\
\hline 18 & $\mathrm{NE}$ & $\mathrm{F}$ & 36 & Operated distal humerus fracture & Posterior & Class IIIC & + & + \\
\hline 19 & $A C$ & $M$ & 44 & Operated distal humerus fracture & Posterior & Class IIIC & + & + \\
\hline
\end{tabular}


Table 3. Comparison of pre- and post- operative mean range of motion of elbow lumn5

\begin{tabular}{|l|l|l|l|l|}
\hline & Pre-operative & Post-operative & Improvement & $p$ value \\
\hline Flexion- Extencion Arc & $27.4^{\circ}$ & $99.2^{\circ}$ & $71.3^{\circ}$ & $p<0.001$ \\
\hline Supination-Pronation Arc & $48.9^{\circ}$ & $102.3^{\circ}$ & $53.4^{\circ}$ & $p<0.001$ \\
\hline
\end{tabular}

Table 4. Comparison of pre- and post-operative average functional scores

\begin{tabular}{|c|c|c|c|c|}
\hline & Pre-орегative & Post-operative & Improvement & $p$ value \\
\hline Q-DASH * & 68.2 & 17.1 & $p<0.001$ & Q-DASH * \\
\hline MEPS ** & 37.5 & 85.6 & $p<0.001$ & MEPS ** \\
\hline
\end{tabular}

At an average follow-up of $36 \pm 8$ months, significant improvement in flexion-extension arc (from $27.4^{\circ}$ to $99 ; 71.3^{\circ}$ improvement) and supination-pronation arc (from $48.9^{\circ}$ to $102.3^{\circ} ; 53.4^{\circ}$ improvement) were noted $(\mathrm{p}<0.001)$ (Table 3). The mean Q-DASH score was decreased from 68.2 to 17.1 and mean MEPS was improved from 37.5 to 85.6 with statistical significance $(\mathrm{p}<0.001)$ (Table 4). At their last follow-up, 13 patients described themselves as very satisfied, 3 patients as satisfied and 3 patients as dissatisfied.

We also compared these results with another cohort from the same institution in which all patients underwent the same type of operation in the presence of intrinsic type elbow stiffness (osteochondritis dissecans, osteoarthritis, inflammatory arthritis, intra-articular fractures, synovial chondromatosis). The improvement in ROM in both planes were statistically significantly higher if $\mathrm{HO}$ was caused by an extra-articular pathology $\left(30.5^{\circ}\right.$ vs. $\left.49.5^{\circ}, \mathrm{p}<0.001\right)$.

A peri-operative supracondylar humerus fracture occurred in 2 patients, which was immediately fixed by plate. Two patients were re-operated for recurrence of ectopic bone formation. No neuro-vascular injuries were noted in any patient.

\section{Discussion}

$\mathrm{HO}$ is a common extrinsic cause of clinically relevant elbow stiffness, which can affect the performance of daily life activities, especially when the dominant side is affected (1-5). Although the exact cause and mechanism leading to $\mathrm{HO}$ formation is not clearly identified, the prevalence in the literature has been reported as 3\%-45\% after any degree of elbow injury $(4-7,9)$. The main aim of this study was to evaluate a single institution's mid-term functional outcomes of open surgical procedures for $\mathrm{HO}$, including the resection of heterotopic bone formation and the release of contracted tissues around the elbow.

According to Abrams et al. (6) patient-related factors, such as gender and age were not associated with HO. Salazar et al. (8) showed that hypertension, high body mass index, and absence of intraoperative anterior ulnar nerve transposition may negatively affect the total flexion-extension arc. Some recent studies showed that longer time to mobilization after elbow injury may be a significant cause of clinically relevant $\mathrm{HO}(5,16)$. Previous studies have also shown that the severity of elbow dislocation correlates with restrictive $\mathrm{HO}(9,17)$. The interval from trauma to surgery and the number of surgical procedures within 4 weeks of injury were found to be related with restrictive $\mathrm{HO}$ (5). On the other hand, the muscle interval used to approach the elbow during surgery may have an influence to the development of $\mathrm{HO}$ (5).

Wiggers et al. (5) reported that although the radiographic evidence of $\mathrm{HO}$ could be found in up to $33 \%$ of patients who had operative treatment of an elbow fracture after at least 4 months following injury, only $10 \%$ of patients had restricted elbow motion. When restriction starts, the timing of surgery is controversial. Charalambous and Morrey (18) recommend surgery for elbow stiffness within a minimum 6 months after injury. Koh et al. (12) showed that surgical results were poor when surgery was performed 19 months after the initial injury. In our study, open release procedure was performed at a mean time of 13 months after first identification of heterotopic ossification formation.

Before the decision of surgical release, both the patient and surgeon should be well aware of the expected benefits and complications after resection of HO. The classic columnar procedure described by Mansat and Morrey (19), is safe and easy procedure to perform and is reliable for an extrinsic elbow stiffness. However, with this lateral approach, it is difficult to release a medial component and ulnar nerve. Capsular release alone cannot resolve the limitation of motion caused by heterotopic bone formation (20). Some authors recommend a posterior approach rather than an anterior, medial, or lateral approach in cases of severe contracture (20). We utilized a posterior approach with using a posterior ulnohumeral bar in cases without severe anterior heterotopic bone formation. We strongly recommend limited dissection in order to prevent hematoma and recurrence of $\mathrm{HO}$ regardless of the surgical approach used.

For activities of daily living, an elbow range of motion of $30^{\circ}$ $130^{\circ}$ flexion/extension and $50^{\circ}$ pronation to $50^{\circ}$ supination is necessary (21). Although restoration of full elbow motion is 
unlikely, improved scores and increased ROM after surgery have been reported (1-3,8,15,22-24). In one of the largest retrospective studies of 39 patients (43 elbows) in whom HO was treated with excision, overall mean flexion-extension arc of motion was improved from $35^{\circ}$ to $103^{\circ}$ at an average of 13 months followup (8). Similarly, in our series, mean flexion-extension arc was improved from $27.4^{\circ}$ to $99.2^{\circ}$ and mean supination-pronation arc was improved from $48.9^{\circ}$ to $102.3^{\circ}$ at an average of $36 \pm 8$ months.

Although patients with an ankylosis gain more increase in motion and in functional scores than those who have limited motion, restoration of normal motion is unlikely (22). The reason for this might be a less extensive surgical approach performed for the patients with partial restriction of motion as compared to patients with ankylosis of the elbow.

Complications are recurrence of $\mathrm{HO}$, fracture during or after operation, infection and wound complications, while nerve palsies are reported as slightly high in the literature $(1,8,13)$. Similarly, we had an overall complication rate of $21 \%$ including intra-operative fracture (two cases) and recurrence of heterotopic bone formation (two cases). Recurrence of $\mathrm{HO}$ is common after excision. The timing of surgery has always been controversial. Classically, surgery is recommended after maturation of the heterotopic bone $(3,4)$.

\section{Study Limitations}

This study has some limitations. The retrospective nature of the study is an obvious limitation. Large prospective series are unlikely to be published because elbow contractures secondary to heterotopic ossification is not a common situation. In addition, the observers in this study were not blinded and a simple goniometer was used for ROM measurements.

\section{Conclusion}

Open surgical release of contracted tissues around the elbow and resection of heterotopic bone formation is a preferable procedure for treating stiff elbow. However, well programmed surgical technique and rehabilitation are required. Excision of heterotopic bone and releasing the contracted elbow capsule can contribute to a substantial rise in scope of motion and improvement in clinical scores. Surgeons must take into consideration the risk of fracture and neurovascular injury during the operation and patients should be followed up closely for the recurrence of stiffness.

\section{Ethics}

Ethics Committee Approval: This IRB approved study includes procedures in accordance with the ethical standards of the institutional and/or national research committee and with the 1964 Helsinki declaration.

Informed Consent: In this study, informed consent was obtained from all participants.

Peer Review: Externally peer-reviewed.

\section{Authorship Contributions}

Concept: M.K., A.C.A., Design: M.K., H.D., Data Collection or Processing: M.K., Analysis or Interpretation: M.K., Y.S., Literature Search: A.E., Writing: Y.S.

Conflict of Interest: No conflict of interest was declared by the authors.

Financial Disclosure: The authors declared that this study received no financial support.

\section{References}

1. Baldwin K, Hosalkar HS, Donegan DJ, Rendon N, Ramsey M, Keenan MA. Surgical resection of heterotopic bone about the elbow: an institutional experience with traumatic and neurologic etiologies. J Hand Surg Am 2011;36:798-803.

2. Maender C, Sahajpal D, Wright TW. Treatment of heterotopic ossification of the elbow following burn injury: recommendations for surgical excision and perioperative prophylaxis using radiation therapy. J Shoulder Elbow Surg 2010;19:1269-75.

3. Ring D, Jupiter JB. Excision of heterotopic bone around the elbow. Tech Hand Up Extrem Surg 2004;8:25-33.

4. Veltman ES, Lindenhovius AL, Kloen P. Improvements in elbow motion after resection of heterotopic bone: a systematic review. Strategies Trauma Limb Reconstr 2014;9:65-71.

5. Wiggers JK, Helmerhorst GT, Brouwer KM, Niekel MC, Nunez F, Ring D. Injury complexity factors predict heterotopic ossification restricting motion after elbow trauma. Clin Orthop Relat Res 2014; $472: 2162-7$.

6. Abrams GD, Bellino MJ, Cheung EV. Risk factors for development of heterotopic ossification of the elbow after fracture fixation. J Shoulder Elbow Surg 2012;21:1550-4.

7. van Kampen PJ, Martina JD, Vos PE, Hoedemaekers CW, Hendricks HT. Potential risk factors for developing heterotopic ossification in patients with severe traumatic brain injury. J Head Trauma Rehabil 2011;26:384-91.

8. Salazar D, Golz A, Israel H, Marra G. Heterotopic ossification of the elbow treated with surgical resection: risk factors, bony ankylosis, and complications. Clin Orthop Relat Res 2014;472:2269-75.

9. Ilahi OA, Strausser DW, Gabel GT. Post-traumatic heterotopic ossification about the elbow. Orthopedics 1998;21:265-8.

10. Winkler S, Wagner F, Weber M, Matussek J, Craiovan B, Heers G, et al. Current therapeutic strategies of heterotopic ossification--a survey amongst orthopaedic and trauma departments in Germany. BMC Musculoskelet Disord 2015;16:313.

11. Kodde IF, van Rijn J, van den Bekerom MP, Eygendaal D. Surgical treatment of post-traumatic elbow stiffness: a systematic review. J Shoulder Elbow Surg 2013;22:574-80.

12. Koh KH, Lim TK, Lee HI, Park MJ. Surgical release of elbow stiffness after internal fixation of intercondylar fracture of the distal humerus. J Shoulder Elbow Surg 2013;22:268-74.

13. Lee EK, Namdari S, Hosalkar HS, Keenan MA, Baldwin KD. Clinical results of the excision of heterotopic bone around the elbow: a systematic review. J Shoulder Elbow Surg 2013;22:716-22. 
14. Akman S, Sonmez MM, Erturer RE, Seckin MF, Kara A, Ozturk I. The results of surgical treatment for posttraumatic heterotopic ossification and ankylosis of the elbow. Acta Orthop Traumatol Turc 2010;44:206-11.

15. Hastings H 2nd, Graham TJ. The classification and treatment of heterotopic ossification about the elbow and forearm. Hand Clin 1994; 10:417-37.

16. Bauer AS, Lawson BK, Bliss RL, Dyer GS. Risk factors for posttraumatic heterotopic ossification of the elbow: case-control study. J Hand Surg Am 2012;37:1422-9.e1-6.

17. Foruria AM, Augustin S, Morrey BF, Sanchez-Sotelo J. Heterotopic ossification after surgery for fractures and fracture-dislocations involving the proximal aspect of the radius or ulna. J Bone Joint Surg Am 2013;95:e66.

18. Charalambous CP, Morrey BF. Posttraumatic elbow stiffness. Indian J Orthop 2017;51:4-13.
19. Mansat P, Morrey BF. The column procedure: a limited lateral approach for extrinsic contracture of the elbow. J Bone Joint Surg Am 1998;80:1603-15.

20. Rhee YG, Cho NS, Lim CT, Yi JW. Debridement arthroplasty for post-traumatic stiff elbow: intraoperative factors affecting the clinical results of surgical treatment. Clin Orthop Surg 2009;1:27-33.

21. Morrey BF, Askew LJ, Chao EY. A biomechanical study of normal functional elbow motion. J Bone Joint Surg Am 1981;63:872-7.

22. Brouwer KM, Lindenhovius AL, de Witte PB, Jupiter JB, Ring D. Resection of heterotopic ossification of the elbow: a comparison of ankylosis and partial restriction. J Hand Surg Am 2010;35:1115-9.

23. Chao EK, Chen AC, Lee MS, Ueng SW. Surgical approaches for nonneurogenic elbow heterotopic ossification with ulnar neuropathy. J Trauma 2002;53:928-33.

24. Tsionos I, Leclercq C, Rochet JM. Heterotopic ossification of the elbow in patients with burns. Results after early excision. J Bone Joint Surg Br 2004;86:396-403. 